\title{
Research on Drain and Counter-Clogging Ability of Porous Asphalt Mixture
}

\author{
Hongchang Wang ${ }^{1,2, *}$, Minggang Zhou ${ }^{1}$, Ming $\mathrm{Li}^{2}$ and Kunitomo Sugiura ${ }^{2}$ \\ ${ }^{1}$ School of Civil Engineering, Nanjing Forestry University, Nanjing 210037, P.R. China; ${ }^{2}$ Graduate School of Engineer- \\ ing, Kyoto University, Kyoto 210037, Japan
}

\begin{abstract}
Porous asphalts pavement arouses the attentions of the world by its good performance such as reduce the potential for hydroplaning, reduce splash and spray, improve visibility, decline traffic noise, and improve driving safety. But the void clogging lessens its durable function. So in this paper appropriate clogging agent was choose, and seepage coefficients were tested by using asphalt mixture pavement surface permeameter to simulation multi-cycle drainage clogging test. The influence of asphalt mixture design parameter such as the porosity, the maximum sizes of the aggregate, gradation and asphalt on the drainage and counter-clogging ability of porous asphalts was researched. The tests indicated that the porosity has an obvious influence on both porous asphalts' permeable ability and counter-clogging ability. Comparing the specimen of $21 \%$ void to the ones of $16 \%$ void, the drain ability is improved $49.8 \%$, the counter-clogging ability is improved $55.0 \%$. The maximum sizes of the aggregate has an obvious influence on porous asphalts' counter-clogging ability, but no an obvious influence on the drain ability. Comparing the specimen of $16 \mathrm{~mm}$ to the $13 \mathrm{~mm}$, the counterclogging ability is proved $48 \%$. PAC with the coarser graduation has a better performance on drain and counter-clogging ability. TPS modifier changes PAC little on drain and counter-clogging ability.
\end{abstract}

Keywords: Clogging, maximum size of the aggregate, porous asphalts, road engineering, seepage coefficient, void.

\section{INTRODUCTION}

Drainage asphalt pavement,that is porous asphalt course (PAC), is refers to the asphalt pavement which surface of a layer or two layer has the function of drainage. Compared with the traditional dense gradation asphalt pavement, $15 \%$ $25 \%$ of void structure in porous asphalt pavement can effectively not only prevent road to form water membrane in the rain, improve the road surface roughness, and reduce vehicle slip, but also reduce tyre raise spray, provide visibility for the driver behind, obviously improve the driving safety. Moreover it can reduce noise of the tyre - pavement reflected from the source [1-3]. Porous asphalt pavement in western countries such as Japan has a history of successful and widely used but has not been popularized in our country. This is because there is a worried about void blocking affecting the functions durability of porous asphalt pavement [4]. And there are many scholars at home and abroad to research on the void and drain ability and counter-clogging ability of porous asphalts, such as Chang'an University studied internal void information of the porous asphalt mixture [5-7]; Southeast University mainly studied the penetration performance of drainage asphalt mixture and deduced infiltration model [8-10]. Hamazah studied counter-clogging performance of single and double PAC by loading congestion solution [11-13]. Kurihara studied the effect of jam dosage on the clogging performance of PAC [14]. But the evaluation on drainage and clogging performance of asphalt mixture should include two stages: the first phase is initial drainage ability of porous asphalt mixture; the second phase is counter-clogging ability of porous asphalt mixture. From the related research, it can be seen that that the study on drainage and anti-clogging ability of PAC is not systematic integrity, the effect of structure parameters and material parameters on the drainage and clogging properties of mixture is not clear, so in this paper the influence law of structure parameter such as void and the maximum nominal size on drainage and anticlogging ability of PAC will be systematic studied by PAC multi-cycle drainage clogging experiment.

\section{EXPERIMENT METHODS}

\subsection{Specimen preparation}

Five types gradation of porous asphalt mixture were designed, by the two types of nominal maximum size of aggregate $(13 \mathrm{~mm}$ and $16 \mathrm{~mm})$ and two kinds of target void $(21 \%$ and $16 \%)$. Each type of porous asphalt mixture gradation is shown in Table 1.

\subsection{Clogging Agent}

Effective clogging test needs appropriate clogging material. In order to simulate the clogging effects better, uniform composition gradation was choose [7]. Finally grain composition of two clogging agent is shown in Table 2. The concentration of clogging agent is quality of blockage fines to water as 1:50. Clogging effect of changes in particle size of clogging agent was studied by choose different type clogging agent. 
Table 1. Porous asphalts' gradation.

\begin{tabular}{|c|c|c|c|c|c|c|}
\hline & & \multicolumn{5}{|c|}{ Mixture gradation type } \\
\hline \multirow{6}{*}{ 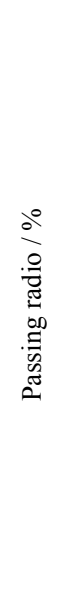 } & $16 \mathrm{~mm}$ & 100 & 98.0 & 100 & 98.0 & 100 \\
\hline & $13.2 \mathrm{~mm}$ & 96.6 & 84.0 & 95.0 & 84.0 & 90.0 \\
\hline & $4.75 \mathrm{~mm}$ & 19.2 & 18.0 & 25.0 & 25.0 & 23.0 \\
\hline & $2.36 \mathrm{~mm}$ & 15.6 & 15.6 & 17.5 & 17.5 & 15.0 \\
\hline & $1.18 \mathrm{~mm}$ & 11.8 & 11.8 & 12.0 & 12.0 & 12.7 \\
\hline & $0.6 \mathrm{~mm}$ & 10.2 & 10.2 & 10.0 & 10.0 & 10.8 \\
\hline \multicolumn{2}{|c|}{$\mathrm{VV} / \%$} & 21 & 21 & 16 & 16 & 21 \\
\hline \multicolumn{2}{|c|}{$\mathrm{BC} / \%$} & 4.32 & 5.16 & 4.31 & 5.13 & 4.78 \\
\hline \multicolumn{2}{|c|}{ NMAS / mm } & 13 & 16 & 13 & 16 & 13 \\
\hline
\end{tabular}

Table 2. Clogging agent composition.

\begin{tabular}{|c|c|c|}
\hline \multirow{2}{*}{$\begin{array}{c}\text { Mesh size } \\
(\mathbf{m m})\end{array}$} & \multicolumn{2}{|c|}{ Passing Radio (by mass)/\% } \\
\cline { 2 - 3 } & Clogging agent a & Clogging agent b \\
\hline \hline 2.36 & 100 & 100 \\
\hline 1.18 & 100 & 83.5 \\
\hline 0.6 & 80 & 66.8 \\
\hline 0.3 & 60 & 50.1 \\
\hline 0.15 & 40 & 33.3 \\
\hline 0.075 & 20 & 16.7 \\
\hline
\end{tabular}

\subsection{Multi-cycle Drain Clogging Test}

With the aid of the asphalt mixture water penetration test (T0730-2011) in 《Standard Test Methods of Bitumen and Bituminous Mixtures for Highway Engineering》(JTG E202011), the specific test steps of multi-cycle drainage clogging test are as follows: (1) firstly mixture penetration test was carried out, and recorded the corresponding time, calculated the initial water penetration coefficient; (2) secondly clogging agent selected concentration was prepared and quantitative $(500 \mathrm{ml})$ joined the pavement seepage instrument to simulate clogging specimen; (3) after clogging test mixture penetration test was carried out again and recorded water penetration time; (4) repeat step (2), (3) until the time of water seepage is more than $3 \mathrm{~min}$. Step (2), (3) is named as one-cycle clogging load.

But the evaluation on drainage and clogging performance of asphalt mixture mainly divided into two parts: one part is asphalt mixture drainage capability before no clogging, char- acterized by the initial water penetration coefficient before loading clogging agent; the other part is counter-clogging ability of porous asphalt mixture, characterized by the number of clogging load cycle. The corresponding maximum size, void and the category of the clogging agent are shown in Table 3. Specimens 9\# adopted the coarse gradation is opposed to specimens $1 \#$, specimens $10 \#$ by the application of high viscosity modified asphalt is opposed to a specimens 1\# (Fig. 1).

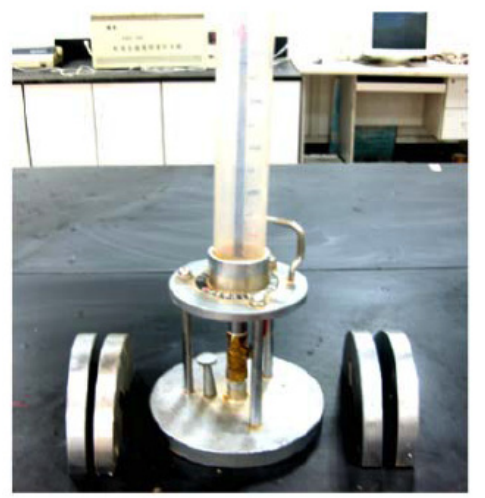

Fig. (1). Pavement surface permeameter.

Penetration coefficient of asphalt mixture is calculated as follow [15]:

$C_{w}=\frac{V_{2}-V_{1}}{t_{2}-t_{1}} \times 60$

where $C_{w}$ is pavement penetration coefficient $(\mathrm{ml} / \mathrm{min})$; $V_{1}$ is the water volume $(\mathrm{ml})$ of the first time, usually for 100 $\mathrm{ml} ; V_{2}$ is The water volume $(\mathrm{ml})$ of the second time, usually for $500 \mathrm{ml} ; t_{1}$ is the first time (s); $t_{2}$ is the second time (s). 
The calculation time is the time needed of the water surface from the dial $100 \mathrm{ml}$ to $500 \mathrm{ml}$. If water penetration time is too long, it also can be calculated by the water volume pass through within the $3 \mathrm{~min}$. So the critical value of water penetration coefficient can be as the $133.3 \mathrm{ml} / \mathrm{min}$ (400 $\mathrm{ml} / 3 \mathrm{~min})$. When the measured water penetration coefficient is less than $133.3 \mathrm{ml} / \mathrm{min}$, the specimen will be identified as blocked to termination the block test.

Table 3. Void, the maximum size of the aggregate and category of the clogging agent.

\begin{tabular}{|c|c|c|c|c|c|}
\hline Mixture & $\begin{array}{c}\text { VV } \\
(\%)\end{array}$ & $\begin{array}{c}\text { Valid VV } \\
(\%)\end{array}$ & Gradation & $\begin{array}{c}\text { NMAS } \\
(\mathbf{m m})\end{array}$ & $\begin{array}{c}\text { Clogging } \\
\text { agent }\end{array}$ \\
\hline \hline 1 & 21.2 & 16.6 & 1 & 13 & $\mathrm{a}$ \\
\hline 2 & 21.1 & 16.8 & 1 & 13 & $\mathrm{~b}$ \\
\hline 3 & 20.8 & 16.2 & 2 & 16 & $\mathrm{a}$ \\
\hline 4 & 21.3 & 15.9 & 2 & 16 & $\mathrm{~b}$ \\
\hline 5 & 16.6 & 11.8 & 3 & 13 & $\mathrm{a}$ \\
\hline 6 & 15.2 & 11.2 & 3 & 13 & $\mathrm{~b}$ \\
\hline 7 & 15.4 & 11.1 & 4 & 16 & $\mathrm{a}$ \\
\hline 8 & 16.0 & 11.9 & 4 & 16 & $\mathrm{~b}$ \\
\hline 9 & 21.0 & 16.2 & 5 & 13 & $\mathrm{a}$ \\
\hline 10 & 20.7 & 15.8 & 1 & 13 & $\mathrm{a}$ \\
\hline
\end{tabular}

\section{RESULTS AND ANALYSIS}

\subsection{Effect of Clogging Agent Particle Size on PAC's Counter-clogging Ability}

First the blocking rule of clogging material particle size on PAC is studied. The clogging test was carried out on the same gradation and void of specimen respectively choose clogging agent type a, type $b$. Test results showed that the cycle number of clogging agent loading with the larger particle size is generally small (only specimen $7 \#$ and $8 \#$ has a contrary). That is said that clogging agent with the maximum nominal size of $1.18 \mathrm{~mm}$ is more easier to block the PAC specimen than clogging agent with the maximum nominal size of $0.6 \mathrm{~mm}$. It can be found the void of $7 \#$ and $8 \#$ drainage asphalt mixture is in the lower limit of the required porosity range, and void of specimens $8 \#$ is greater than specimens $7 \#$, therefore this contrast is also acceptable (Fig. 2).

\subsection{Effect of Porosity on PAC's Drain and Counter- clogging Ability}

Loading times of 0 is characterized initial drainage capacity of the porous asphalt mixture. From Figs. (3 and 4) it is obvious that the more void of PAC is, the greater initial drainage ability is. The average initial water penetration coefficient of the mixture specimens $(1 \# \sim 4 \#, \mathrm{VV}$ is about $21 \%$ ) is $6361.5 \mathrm{ml} / \mathrm{min}$, and the average initial water penetration coefficient of the mixture specimens $(5 \# \sim 8 \#, \mathrm{VV}$ is about $16 \%$ ) is $3129.3 \mathrm{ml} / \mathrm{min}$. The initial water penetration coefficient of mixture specimens $(1 \# \sim 4 \#)$ is significantly greater than that of mixture specimens $(5 \# \sim 8 \#)$. The average initial water penetration coefficient of the specimens for void of $21 \%$ compared to void of $16 \%$ is increased by $49.8 \%$. That is say the greater PAC void is, the stronger drainage ability is.

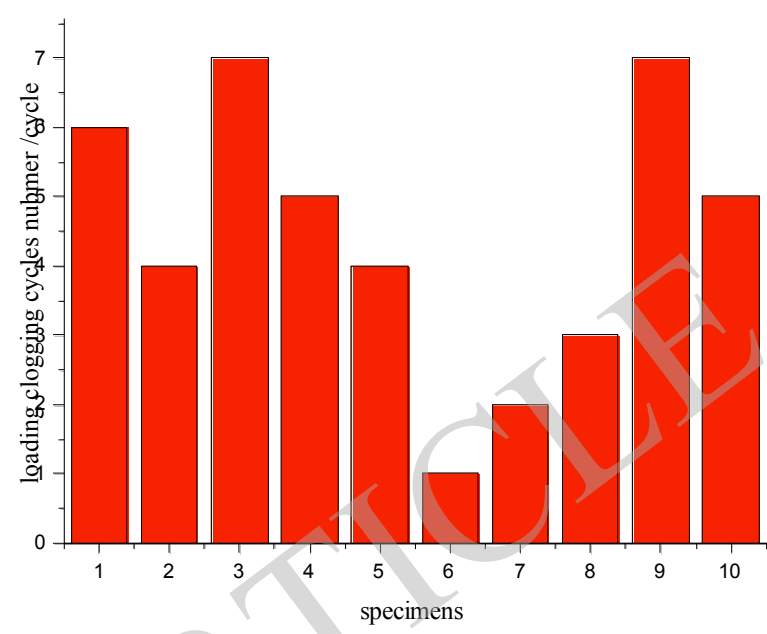

Fig. (2). Porous asphalts' clogging times.
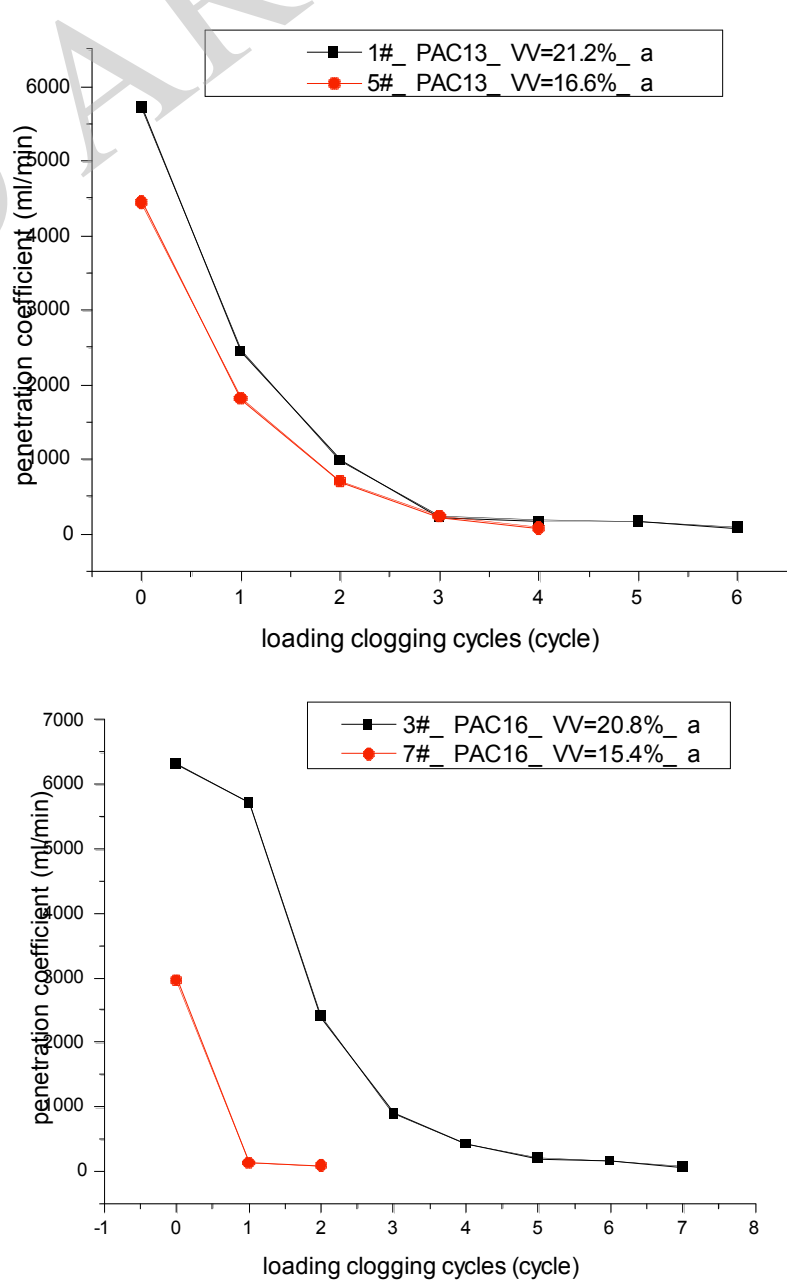

Fig. (3). Clogging times and penetration coefficients in different void by agent a. 


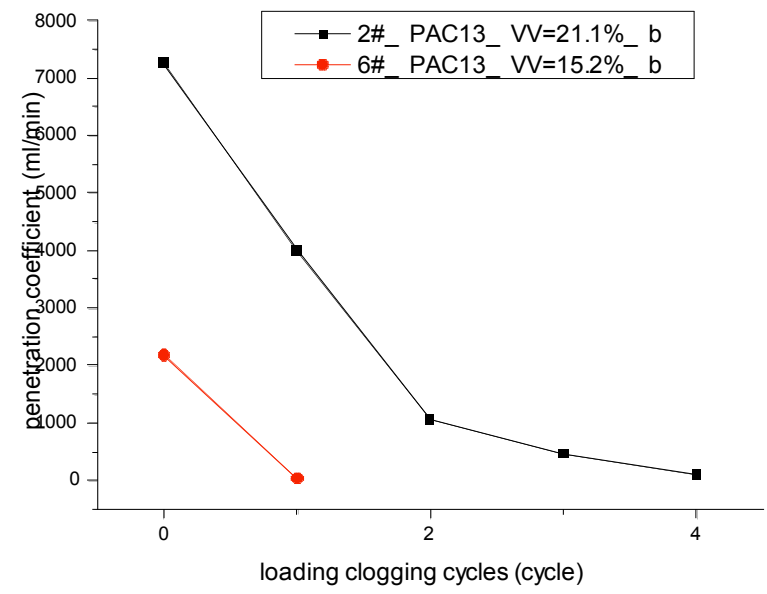

nominal size of $16 \mathrm{~mm}$ compared to that of $13 \mathrm{~mm}$ increased by only $2.3 \%$. This is further illustrated the main factor to affect the initial drainage capacity of PAC is void.

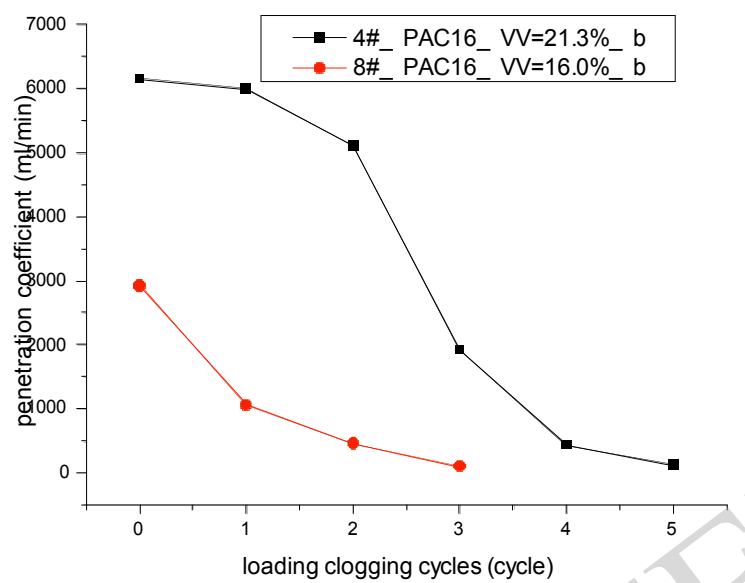

Fig. (4). Clogging times and penetration coefficients in different void by agent $b$.

Compared by clogging loading cycle number of $1 \#$ to $5 \#$, $2 \#$ to $6 \#, 3 \#$ to $7 \#, 4 \#$ to $8 \#$, it is known that the clogging loading cycle number of larger void mixture specimen is higher than that of small voids mixture specimen, the clogging loading cycle number of specimens with VV of $21 \%$ is more 3 cycles than that of specimens with VV of $16 \%$. The counter-clogging ability of porous asphalt mixture with more voids is stronger than that of mixture with fewer voids. That is to say, the greater the void ratio of asphalt mixture is, the stronger counter-clogging ability is.

As medium of water seepage, PAC drainage ability is based on several continuous channels from one specimen's side to the other [16]. The greater void of asphalt mixture is, the greater the channel number is, and so the stronger the PAC drainage ability is. And that the number of channels no blocking is more in loading the same clogging agent shows the good drainage performance. This also indicates that the water penetration coefficient can reflect the presence of PAC internal aperture channels.

\subsection{Effect of Maximum Nominal Size on PAC's Drain and Counter-clogging Ability}

As you can see from Figs. (5 and 6), the effect of the maximum nominal size on the initial drainage capacity of PAC specimens is not obvious. The average initial water penetration coefficient of the specimen with maximum

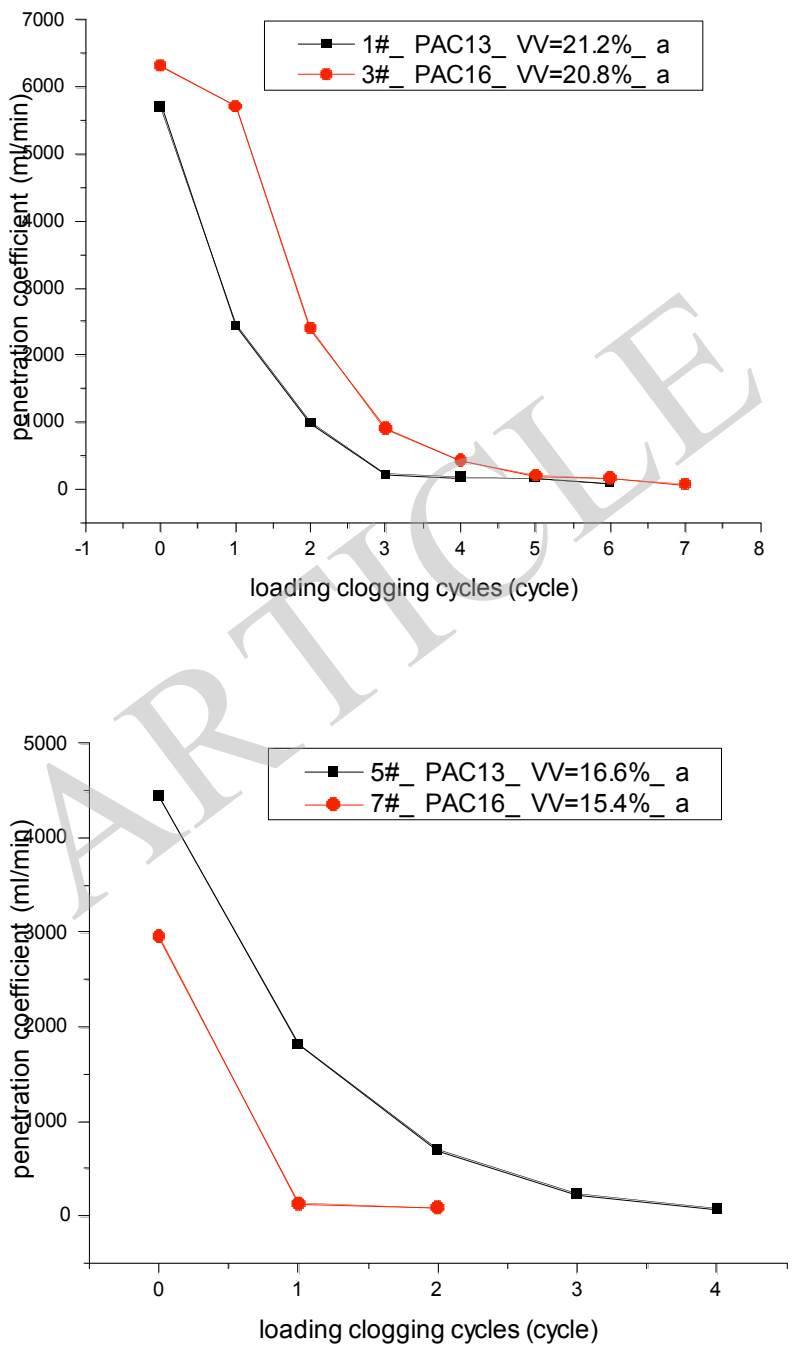

Fig. (5). clogging times and penetration coefficients in different aggregate maximum size by agent a.

Compared to $1 \#$ and $3 \#, 2 \#$ and $4 \#, 6 \#$ and $8 \#$, it can be found that the clogging loading cycle number with the maximum nominal size of $16 \mathrm{~mm}$ is increased $48 \%$ on average than that of $13 \mathrm{~mm}$. The results shows that PAC specimen with a larger the maximum nominal size has the better counter-clogging effect. There is abnormal at loading number of specimens $5 \#$ and $7 \#$. That is because the smaller void of specimen $7 \#$ reduces the counter-clogging ability.

\subsection{Effect of Coarse, Fine Gradation and Asphalt Type on PAC's Drain and Counter-clogging Ability}

Compared by the specimens of $1 \#$ and 9\# in Fig. (7), it can be seen that gradation has significantly influence on PAC drainage ability. At the same void, the initial drainage and counter-clogging ability of the coarse gradation is both better than that of fine gradation. 

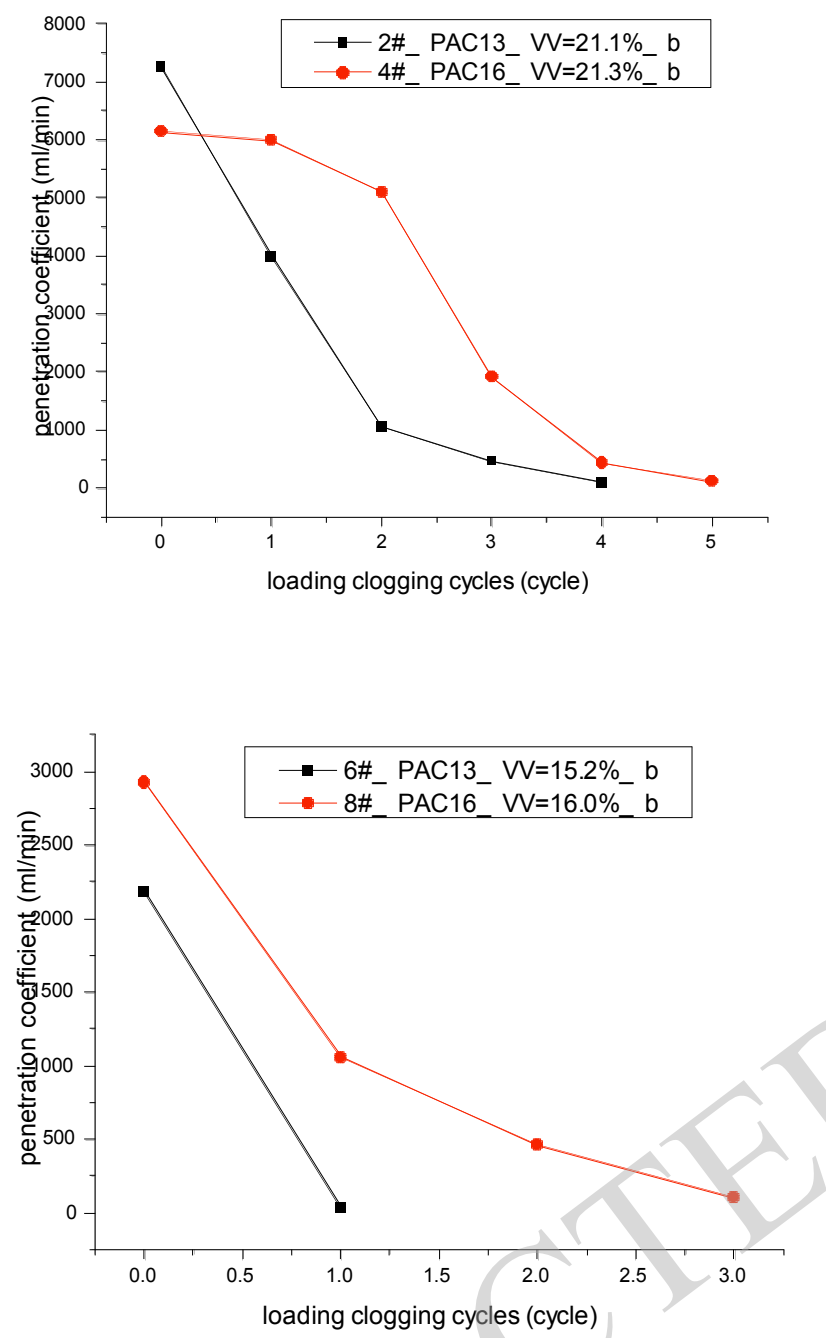

Fig. (6). clogging times and penetration coefficients in different aggregate maximum size by agent $b$.

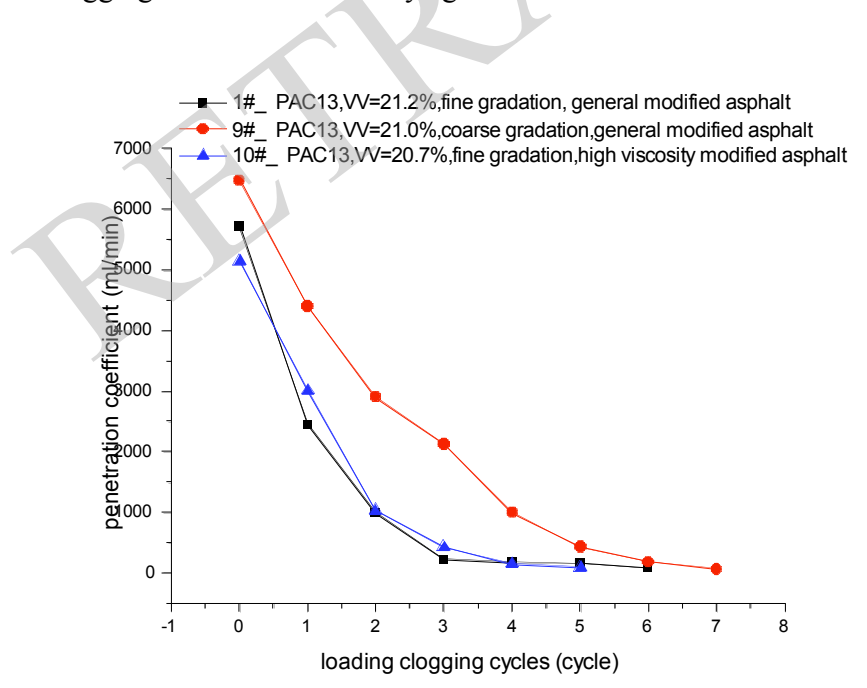

Fig. (7). The clogging times and corresponding water penetration coefficients of porous asphalts in different gradations and asphalts
Special after in the first four cycles of loading clogging agent, drainage ability of coarse gradation specimens is better than that of fine gradation. So at the conditions that other structural parameters are the same, the coarse gradation PAC has the stronger drainage and counter-clogging ability. This is because the large particle size of aggregate contacted to each other sets aside the gap larger than smaller particle size of aggregate, and not easy to be blocked by clogging agent.

Compared by $1 \#$ and $10 \#$ in Fig. (7), it can be found that drainage and counter-clogging ability of PAC has little impact by the use of high elastic asphalt.

\section{CONCLUSION}

(1) The multi-cycles drainage and clogging test was put forward by using pavement seepage meter. Through the determination of the initial water penetration coefficient and cycle-numbers of loading clogging the drainage and counter-clogging ability of asphalt mixture was evaluated.

(2) The average initial water penetration coefficient of the specimens $(\mathrm{VV}=21 \%)$ compared to the specimens $(\mathrm{VV}=16 \%)$ is increased by $49.8 \%$. Cycle-numbers of load clogging for the specimens $(\mathrm{VV}=21 \%$ ) compared to the specimens $(\mathrm{VV}=16 \%)$ is increased by $55 \%$ on average.

The greater void of asphalt mixture is, the stronger drainage and counter-clogging ability are.

(3) The average initial water penetration coefficient of specimens with the diameter of $16 \mathrm{~mm}$ compared to that of $13 \mathrm{~mm}$ increased by only $2.3 \%$, there is no obvious effect of biggest diameter variation on its ability to drainage, but cycle-number of loading clogging of specimens with the size of $16 \mathrm{~mm}$ compared to that of $13 \mathrm{~mm}$ is increased $48 \%$ on average, so PAC specimen with larger maximum nominal diameter has better counter-clogging ability.

(4) The coarse gradation of PAC has stronger ability of drainage and counter-clogging. Asphalt type does not affect the PAC drainage and anti-clogging ability.

\section{CONFLICT OF INTEREST}

The authors confirm that this article content has no conflict of interest.

\section{ACKNOWLEDGEMENTS}

This work was supported by A Project Funded by the Priority Academic Program Development of Jiang'su Higher Education Institutions (PAPD), the Science Research for Ministry of Housing and Urban-Rural Development (2011K5-17) and Jiang'su Overseas Research \& Training Program for University Prominent Young \& Middle-aged Teachers and Presidents.

\section{REFERENCES}

[1] H. Wang, and X. Huang, "Finite element analysis for noisereducing of double-layer porous asphalt pavement," Chinese Journal of Environmental Engineering, vol. 5, no. 12, pp. 2910-2914, 2011. 
[2] H. Wang, "Analysis of surface crack propagation and fatigue life of granular base asphalt pavement," Journal of Nanjing Forestry University (Natural Science Edition), vol. 34, no. 2, pp. 111-114, 2010.

[3] P. Wei, "Study n water stability of OGFC asphalt mixes[J]." Highway Engineering, vol. 38(3), pp. 15-17, 2013.

[4] B. Xu, "The Theory and Practice of Porous Asphalts," [M]. China Communications Press. vol. 6, pp. 7-10, 2011.

[5] J. Pei, "Void spatial information acquisition method of draining asphalt pavement," Journal of Chang'an University (Natural Science Edition), vol. 30, no. 1, pp. 6-11, 2010.

[6] H. Wang, "Distribution properties of internal air voids in asphalt mixtures," Journal of Traffic and Transportation Engineering, vol. 9, no. 1, pp. 6-11, 2009.

[7] H. Xu, F. Ni, and Q. Liu, "Research hydraulic conductivity of porous asphalt mixture," China Journal of Highway and Transport, vol. 17, no. 3, pp. 1-5, 2004.

[8] Y. Zhu, "Research on Drainage Performance and Design of Drainage Structure on the Porous Asphalt Pavement," Southeast University: School of Transportation Southeast University, pp. 6-31, 2004.

[9] F. Zhang, "Techniques of permeability testing for porous asphalt pavement mixture," Journal of Southeast University (Natural Science Edition), vol. 40, no. 6, pp. 1288-1292, 2010.
[10] X. Ma, "Test and Analysis on Permeability of Porous Asphalt Mixture," Journal of Building Mterials, vol. 12, no. 2, pp. 168-172, 2009.

[11] M. O. Hamzah, and Hardiman, "Characterization of the Clogging Behaviour of DoubleLayer Porous Asphalt," Journal of the Eastern Asian Society for Transportaion Studies, pp. 968-980, 2005.

[12] "Double Layer Porous Asphalt in the Netherlands and Field Monitoring in Belgium," The School of Civil Engineering University. Meor Othman on the Eastern Asia Society for Transportation Studies, vol. 6, 2007.

[13] T. R. Elvik, and P. Greibe, "Road safety effects of porous asphalt: A systematic review of evaluation studies," Accident Analysis and Prevention, vol. 37, no. 3, pp. 515-522, 2005.

[14] O. Kurihara, "Experimental study on the clogging of voids of porous asphlt," Shibaura Institute of Technology Campus Tokyo's: Technical Workshop 35th Kanto Branch Society of Civil Engineers, 2008.

[15] J. Yi, "Criterion of Air Voids Based on Permeability Characteristic of Aspalt," Journal of Highway and Transportation Research and Development, vol. 26, no. 9, pp. 17-19, 2009.

[16] X. Kong, "Advanced Seepage mechanics," Press of University of Science and Technology of China: China, pp. 12-41, 2010.

Received: February 03, 2015

Revised: April 03, 2015

Accepted: May 25, 2015

(C) Wang et al.; Licensee Bentham Open.

This is an open access article licensed under the terms of the (https://creativecommons.org/licenses/by/4.0/legalcode), which permits unrestricted, noncommercial use, distribution and reproduction in any medium, provided the work is properly cited. 